\title{
The Odyssey of a Polymer Chemist in Switzerland
}

\author{
Martin Roth*
}

\begin{abstract}
A personal survey of some of the polymer-related work which I had the chance to carry out in CibaGeigy's Central Research and in the polymer departments of Ciba SC, Vantico and Huntsman is given, including a few short comments on the eventful history of the former Ciba-Geigy Central Research and Polymer Division. In the early 1970s, high-temperature-stable aromatic [polyamide - polyimide] block copolymers and the relatively easy processable bismaleimides as high-temperature thermoset materials were the dominant theme. Work on photocrosslinkable DMI polymers which ultimately led to the development of a non-silver graphic film and a presensitized negative offset printing plate was pursued at the Centre de Recherche Marly. In the field of epoxy resin chemistry, 'latent' hardeners, featuring a relatively long pot-life at room temperature and a short cure cycle at the processing temperature, were devised in the form of benzyl-sulfonium salts and imidazole-functionalized microgels. Ciba-Geigy's polymer division has pioneered the development of liquid, photoimageable soldermasks with it's Probimer ${ }^{\circledR}$ range of products. Here binderpolymers constitute the main components of the complex formulation recipes. High molecular weight polymers carrying acryloyl and carboxyl functional groups were synthesized for this purpose and have found commercial application in new soldermask generations.
\end{abstract}

Keywords: Binderpolymers for soldermasks - Benzylsulfonium salts as fast curing agents for epoxy resins . High temperature stable polymers - Microgel-imidazole adducts as latent epoxy curing catalysts .

Photocrosslinkable DMI-polymers

\section{Introduction}

Large volumes of commodity plastics have never been produced in Switzerland and polymer-related academic and industrial activities, scattered over many locations and scientific disciplines, are thus less apparent than those of the dominant pharmaceutical and fine chemicals industries. Indeed, polymers played and play a significant role in multiple areas of our industrial landscape as well as in academic research, and important achievements such as the pioneering work on epoxy resins could be mentioned. A host of small- and medium-sized companies are active in the processing of polymers, and

${ }^{\star}$ Correspondence: Dr. M. Roth Holenweg 44

$\mathrm{CH}-4434$ Hölstein/BL

Tel: +410619511476

E-mail: martin.roth@bluewin.ch equipment for polymer processing is one of the pillars of the Swiss machine industry.

In this article a personal review of some of the polymer-related work which I had the chance to accompany in my working life is given. It is not exemplary but might give young scientists seeking a position in polymer or industrial chemistry a flavor of what to expect.

\section{High Temperature-stable Polymers}

In 1972, when I began my professional career in Ciba-Geigy's Macromolecular Chemistry Section of the Central Research Department, the merger of Ciba and Geigy to create the new giant had just occurred. A consequence of that 'marriage' had been the birth of a Central Research function, providing a means of searching for new and hopefully profitable areas in chemistry. Most major chemical companies at that time featured this type of additional research structure, granting a certain distance and independency from the focused research activities of the business divisions. Historically the Basel chemical industry had always been powered by diversification and there was no sign that this principle wouldn't hold true any more. The retreat to core business occurred actually much later.

The Macromolecular Chemistry (MC) section, headed by Prof. Gerd Greber, stood as a relatively humble unit beside the much bigger organic chemistry and analytical units of Central Research (CR). Nevertheless, varied polymer and materials related activities were pursued and chemists were held on a relatively long leash - an amount of 10-20\% of working hours to follow up one's own ideas was said to be possible a blessing which was not to continue into subsequent decades. Research activities were centered around silicone chemistry, heat stable polymers, photosensitive polymers and polymer processing.

The early 1970s witnessed a dramatic growth of the aerospace, defence and electronic industries. New polymers able to be processed by thermoplastic methods and exhibiting long-term stability at temperatures up to $250{ }^{\circ} \mathrm{C}$ without loss of mechanical and electrical properties were required. Intensive research aiming for such high performance engineering plastics was going on at major polymer manufacturers. This topic became also dominant in our MC section, where we were trying to impart the ability of thermoplastic processing to aramide- and polyimide-type polymer structures (Scheme 
1). These polymers were known to be notoriously difficult to process - aramides (fully aromatic polyamides) existed only in fiber form and had to be wet spun from exotic solvents; polyimides in their fully imidized form such as Kapton ${ }^{\circledR}$ were completely insoluble and infusible and films had to be cast from a precursor, the polyamide-acid solution, and then thermally cyclized to the imide form.

A known strategy to improve processing is to weaken molecular interactions between polymer chains, either by placing large side groups along the chain or by disturbing the molecular order within the chains, e.g. through copolymerization. Using the latter approach, Darms, Greber and Lohmann developed aromatic [polyamide - polyimide] block copolymers, socalled PAPI's (Scheme 1). ${ }^{[1]}$ In principle, separate oligomeric polyamide blocks $\mathbf{1}$ and polyamide-acid blocks 2 were prepared and then coupled via the end groups. This approach leaves a lot of freedom for variations. A preferred route was a one-pot process, starting with e.g. pyromellitic or 4,4'-benzophenonetetracarboxylic acid dianhydride and a sub-stoichiometric amount of 4,4'-diaminodiphenylether yielding the polyamide-acid block 2 with anhydride end groups. $m$-Phenylenediamine was then added to this reaction solution in NMP (Nmethylpyrrolidone), followed by isophthaloylchloride, thus forming the polyamide block 1 with amine end groups and simultaneously joining the two blocks via amide bonds. The $\mathrm{HCl}$ formed was removed by reaction with propylene oxide. The homogeneous solution of the polyamide - polyamide-acid 3 could be converted to the imidized form 4 with acetic anhydride, and the solid polymer $\mathbf{4}$ isolated by precipitation in water. Small parts were produced by compression molding at around $300{ }^{\circ} \mathrm{C}$ without decomposition. Later, polymer $\mathbf{4}$ was found to possess very good adhesion to copper which rendered it suitable as a matrix resin for the manufacture of high-temperature laminates for printed wiring boards.

Bismaleimides (Scheme 2), which had been earlier commercialized by RhonePoulenc $\left(\right.$ Kerimide $\left.^{\circledR}\right)$, provided another topic that attracted our interest. The pronounced reactivity of the maleimide function towards polymerization and Michael type nucleophilic addition forms the basis for crosslinking ('curing') reactions. Admixtures of bis-maleimide 5 with aromatic diamines such as DDM (4,4'-diaminodiphenylmethane) 6 and catalysts led to relatively easily processable high-temperature thermoset materials. Later developments by Ciba-Geigy (Dr. S.A.C. Zahir) gave rise to the Matrimid ${ }^{\circledR} 5292$ system (now Huntsman), which nowadays is widely used for high-temperature composites and high-performance adhesives.

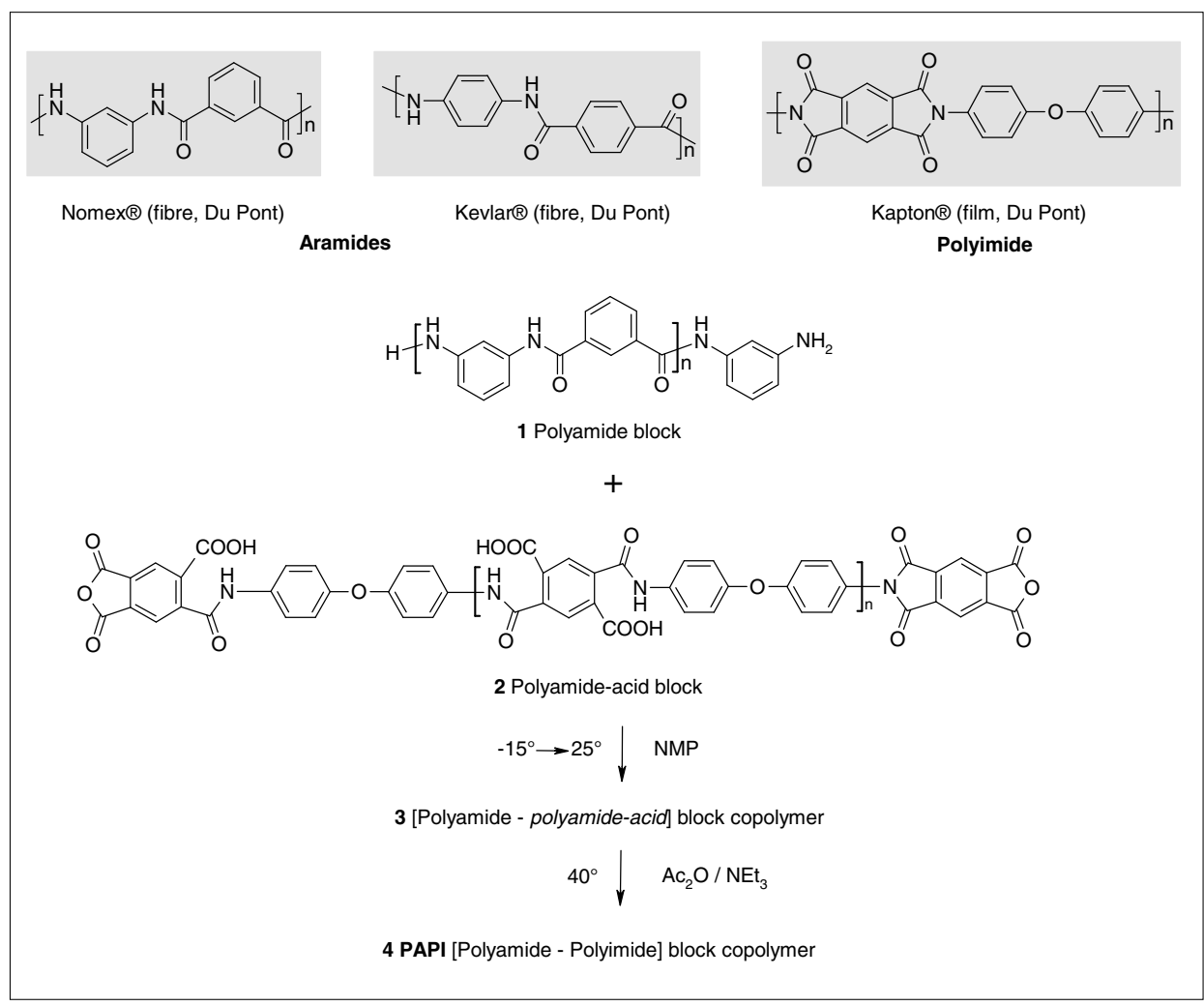

Scheme 1. Heat-stable [polyamide-polyimide] block copolymers

Kerimid@:
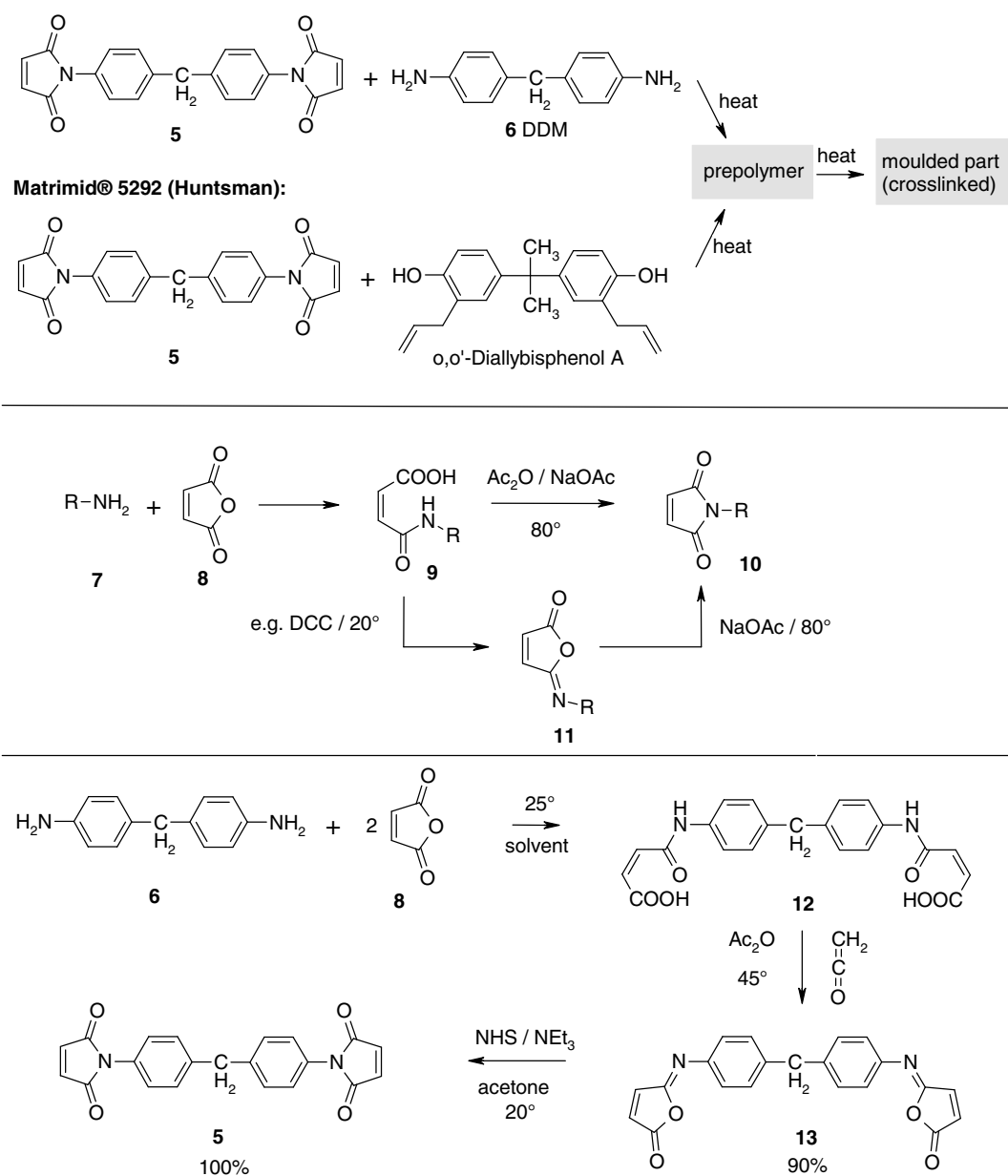

Scheme 2. Bismaleimides and isoimides 
Maleimides are generally prepared by a two-step process, starting from an amine 7 and maleic anhydride $\mathbf{8}$. The intermediate maleamic acid 9 is then cyclized to the imide $\mathbf{1 0}$ with acetic anhydride as dehydrating agent and sodium acetate or triethylamine as a base. At that time, the reliable synthesis of the bismaleimide $\mathbf{5}$ proved to be quite difficult, with process impurities and yield as the critical issues. Minor variations in reaction conditions resulted in varying amounts of side-products, and purification was not feasible due to cost reasons. Interestingly, lower reaction temperatures and highly reactive dehydrating agents such as DCC (dicyclohexylcarbodiimide) or acetyl chloride in the cyclization step lead to relatively stable, isomeric 'isoimides' (iminolactones) 11, which rearrange thermally to the thermodynamically preferred imides 10. It occurred to us that such mild reaction conditions could provide a beneficial route to maleimides. Using ketene as a potentially cheap dehydrating agent and a special catalyst for the low temperature rearrangement, we were able to prepare 5 in excellent yield and purity (Scheme 2). An excess of gaseous ketene (from a ketene lamp) was bubbled through a suspension of the maleamic acid 12 in acetic anhydride as solvent at $40-45{ }^{\circ} \mathrm{C}$ and the isoimide 13 isolated by evaporation. Treatment of a solution of $\mathbf{1 3}$ in acetone with catalytic amounts of $\mathrm{N}$ hydroxysuccinimide (NHS) or phenol and triethylamine at room temperature afforded the bismaleimide 5 in quantitative yield. [2] Quite to our disappointment no commercial realization for this project could be envisaged and the isoimide work came to a halt when new challenges appeared on the horizon.

\section{Photocrosslinkable DMI-Polymers}

In 1977 I accepted a position at the Centre de Recherche in Marly/FR (CRM) as head of the 'Unconventional Photography' group. The Marly site, belonging to Ciba-Geigy's Ilford Division, produced the famous Cibachrome ${ }^{\circledR}$ color photographic material, and the CRM, under the direction of Dr. P. Junod, focused on physical chemical research in photography. At that time, silver halide containing gelatine emulsions formed the basis of nearly all photographic materials - the digital revolution was still far away.

In 'Unconventional Photography' we aimed at developing non-silver photographic systems, and light-sensitive polymers of the type used in photoresist technology were considered a viable approach to achieve this. Finter, Zweifel and others ${ }^{[3]}$ at CR Basel had shown that polymers carrying pendent dimethylmaleimide (DMI) groups

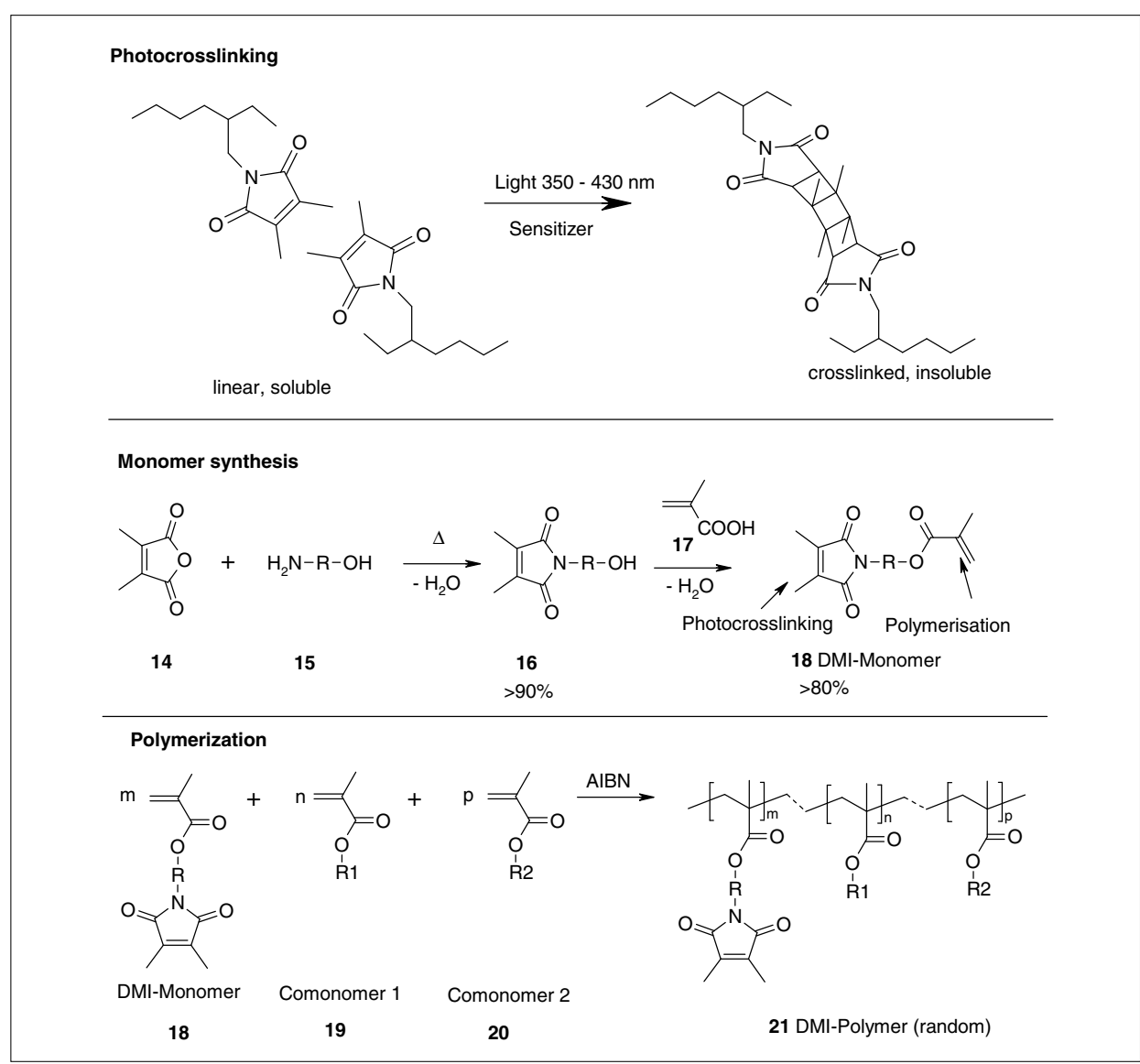

Scheme 3. Photocrosslinkable DMI-polymers

could be easily photocrosslinked by irradiation with near UV light (Scheme 3). These polymers were readily accessible thanks to Baumann's simple and economic synthesis of dimethylmaleic anhydride (DMA) 14. ${ }^{[4]}$ Two principal pathways existed for the polymer synthesis: either polymer analogous reactions, ${ }^{[5]}$ e.g. reacting DMI-functional acid chlorides with polyvinylalcohol, or polymerization of DMI-functional monomers. ${ }^{[6]}$ The latter was chosen as it was anticipated that it would offer much more freedom for variations. Monomer synthesis proceeded in two simple steps as outlined in Scheme 3. Reacting an aliphatic (or aromatic) aminoalcohol 15 with DMA 14 was straightforward and yielded the intermediate DMI-alcohol 16 without the need for dehydrating agents. Esterification with methacrylic acid 17 under azeotropic removal of water furnished the DMI-monomer 18 in high yield. The 'dual functional' monomer $\mathbf{1 8}$ merges the concepts of radical polymerization via the methacrylic group with photocrosslinking via the DMI group. The approach only works because the sterically hindered tetrasubstituted carbon-carbon double bond of the dimethylmaleimide does not participate to any extent in the polymerization reaction, as opposed to most other photocrosslinkable groups (notably cinnamates).

Copolymerization of the monomer $\mathbf{1 8}$ with one or more comonomers 19, 20 was performed in solution with radical initiators such as AIBN (azo-bisisobutyronitril) and yielded soluble DMI-copolymers 21 with statistical distribution of the monomer units within the chain. Practically 100\% monomer conversion could be realized, so that the resulting polymer solution could be put directly to further use without the need for precipitation - an important factor for any scale up to large quantities. Tailoring of important polymer properties such as solubility, glass transition temperature (Tg), molecular weight and DMI-group content was possible due to a proper choice of monomers.

The photocrosslinking and concomitant insolubilization of DMI-polymers result from the photoinitiated $(2+2)$ cycloaddition reaction of the pendent DMI groups.

As the DMI chromophore absorbs in the deep UV region of 270-300 nm, sensitization with triplet sensitizers is necessary in order to be able to use conventional UV light sources with an emission maximum at 340-430 nm. Meier and Zweifel[7] had shown that thioxanthone esters were particularly suited for this purpose. Given these highly interesting properties of DMIpolymers, a group composed of B. Müller, J. Berger and myself, embarked on a search for some technical applications.

A first achievement was the realization of a silverless photopolymer contact film 


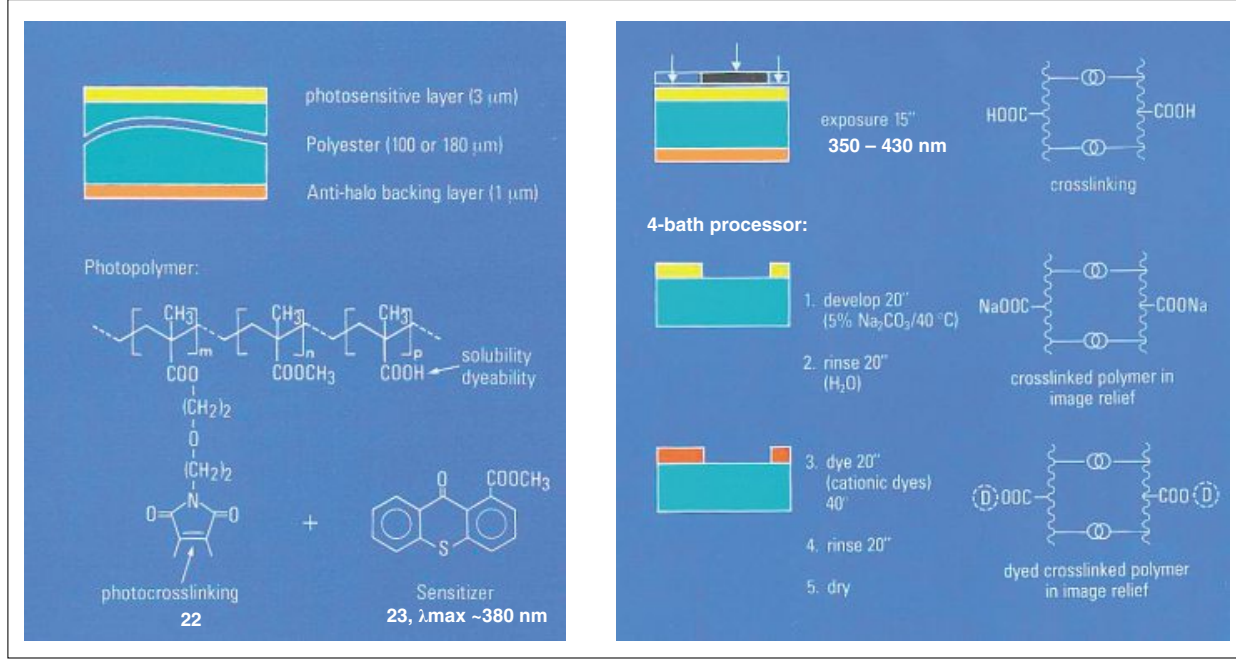

Fig. 1. Densolite ${ }^{\circledR}$ photopolymer film

(Densolite ${ }^{\circledR}$ ) for graphic arts application (Fig. 1). ${ }^{8]}$ A transparent photographic polyester film base was coated on one side with a specially designed, colorless DMI-polymer 22 and sensitizer 23 forming the photosensitive layer, and on the reverse side, a thin orange colored antihalation layer served to improve resolution by absorbing back scattered UV light during exposure. Methacrylic acid in the DMI-polymer 22 imparted two important properties: developability in weakly alkaline aqueous solutions and dyeability with cationic colorants. The absorption maximum $\lambda \max =380 \mathrm{~nm}$ of the thioxanthone sensitizer $\mathbf{2 3}$ ensured that the film could be handled under normal room-light conditions without the risk of unwanted exposure.

After contact exposure through a photographic negative in a conventional exposure frame with near UV light, processing was done in an automatic four bath processor (5\% sodium carbonate developer - water rinse - dye bath - water rinse). Dissolution of the non-exposed parts of the photopolymer layer in the alkaline developer left an image relief which was permanently dyed with cationic dyes via fixation to the carboxylic acid groups. The cationic dye mixture was chosen to give the polymer image an optical density of $>4.0$ at $350-500 \mathrm{~nm}$. Despite this high UV blocking density the red image was transparent. Due to the high thermal stability of DMI-polymers in general, the film had a long shelf-life at elevated temperature and humidity. Given these interesting characteristics, special graphic arts applications such as phototools in PWB manufacturing or cartography could be envisaged. However with Ciba-Geigy not being active in these fields, the technology was subsequently licensed to the Swiss firm Folex under the trade name Densolite ${ }^{\circledR}$. Minor quantities were sold until the 1990 's, when the advent of digital imaging rendered it obsolete.
Another practical outlet concerned the use of DMI-polymers as light-sensitive coatings for offset printing plates. As a detailed description is outside the scope of this article, it is sufficient to say that such offset printing plates are still on the market today.

\section{Fast Curing of Epoxy Resins: Benzylsulfonium Salts}

1981 witnessed some marked changes at the Marly site. Restructuring within the Ilford Division caused the closing of CRM, followed by the transfer of the Kunststoff - Additiv (KA) Division's research departments from Basel to Marly. With some melancholy we waved good-bye to the golden days of Central Research but were happy to land in the safe haven of the 'KunststoffForschung', then headed by Dr. R. Darms. Being part of a business unit, a considerably stiffer wind was felt in terms of project assessment and handling.

Undeniably, epoxy resins (Araldite ${ }^{\circledR}$ ) with all their application facets were the bread and butter of Ciba-Geigy's Polymer division (and are still the mainstay of Huntsman's Advanced Materials), and being part of that unit, we were increasingly exposed to some of the burning research problems in the epoxy area. In the mid 1980 s, our group (B. Müller, P. Flury, H. Wolleb and myself) was engaged in research activities on various aspects of epoxy resins, such as laminating and encapsulating systems, flame retardant epoxies and resin synthesis.

Epoxy resin chemistry is a fascinating subject, both from a chemical and an engineering point of view, as the scope of resins, hardeners and their practical usage is almost unlimited. If properly formulated and fully cured they have good dielectric properties, a low thermal coefficient of expansion, excellent chemical resistance and good adhesion to metals. However, as thermoset materials they also show some inherent drawbacks: brittleness due to their crosslinked structure and relatively long cure cycles in processing when compared to thermoplasts. The latter issue attracted our attention as there was an increasing demand for fast curing epoxy molding compounds e.g. for chip encapsulation. So-called 'catalytic' hardeners were known to imply fast curing rates in certain epoxy resins, acting as cationic or anionic initiators for the ring-opening homopolymerization of the strained epoxy group. Preliminary work in our division had shown that some cationic metal complexes with non-nucleophilic anions in combination with cycloaliphatic epoxy resins could provide very high cure speeds but at the expense of any pot-life (usage time of the ready-to-use formulation) at ambient temperature. Aiming at systems with an improved 'latency', i.e. having a longer pot-life at room temperature and a short geltime at cure temperature, we embarked on a search for alternative cationic thermal hardeners.

Screening of potential candidates was a relatively simple task involving DSC measurements (Differential Scanning Calorimetry) and geltime determinations. DSC curves provide ample information about primary cure characteristics such as reaction onset, reaction enthalpy, peak temperature and $\mathrm{Tg}$, whereas the geltime is a simple, qualitative measure of cure speed.

Sulfonium salts attracted our interest. Triaryl sulfonium salts were already in use as effective cationic photoinitiators but, due to their high thermal stability, not suitable for our purpose. Various thermally less-stable trialkyl sulfonium salts, although occasionally cited in the literature as cationic polymerization initiators, ${ }^{[9]}$ gave unsatisfactory test results. Things changed drastically when benzyl substituted sulfonium salts with nonnucleophilic anions (Scheme 4) were synthesized and screened, as they were found to feature a very interesting spectrum of properties. The monobenzyl sulfonium salts 24-26[10] were tested in a cycloaliphatic resin (Araldite CY 179) and a bisphenol A type resin (Araldite GY 260), each containing $2 \mathrm{wt} \%$ of sulfonium salt hardener. Table 1 shows that the geltimes of the cycloaliphatic formulations at $140{ }^{\circ} \mathrm{C}$ were considerably faster than those in the case of bisphenol $\mathrm{A}$ at $170{ }^{\circ} \mathrm{C}$, as could be expected from the known high reactivity of cycloaliphatic resins with cationic hardeners. The hexafluoroantimonate $\mathbf{2 4}$ proved to be clearly superior to the hexafluorophosphate $\mathbf{2 5}$ and even more so to the tetrafluoroborate $\mathbf{2 6}$ and therefore the hexafluoroantimonate anion was chosen for all subsequent studies.

Yet, besides the fact that these compounds had already been patented, the cure speeds weren't high enough for our pur- 


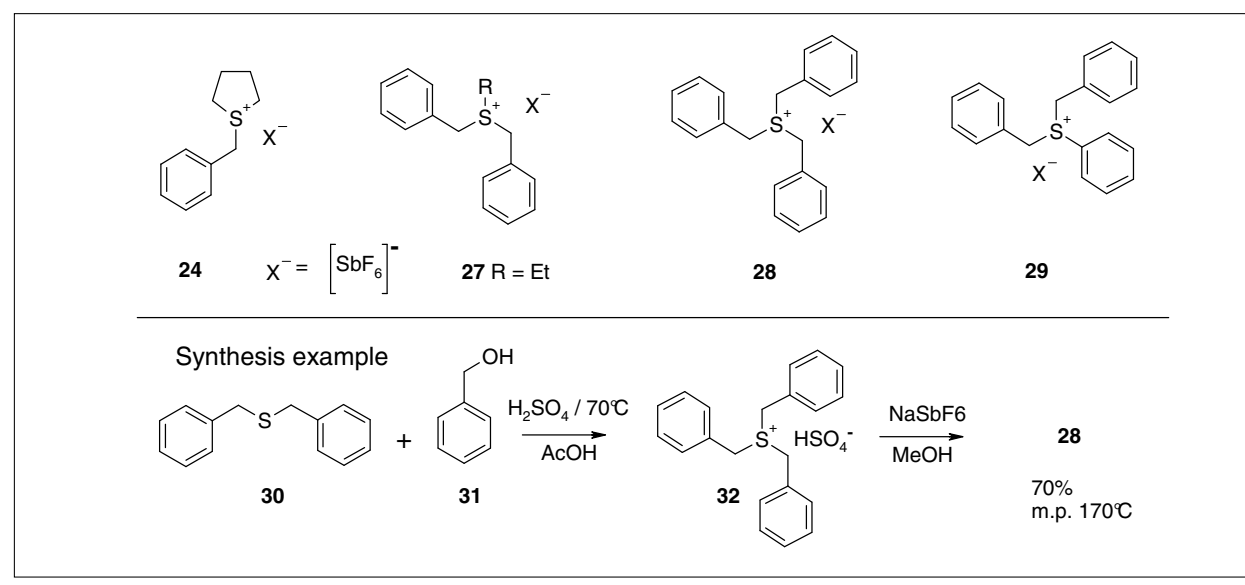

Scheme 4. Benzylsulfonium salts as catalytic hardeners for epoxy resins

Table 1. Geltimes ${ }^{\mathrm{a}}$ of monobenzylsulfonium salts with various anions in cycloaliphatic and bisphenol A type epoxy resins (2\% in resin)

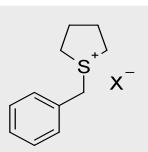

$2 \%$ in epoxy resin

$\mathrm{X}=\mathrm{SbF}_{6}(24$

$\mathrm{X}=\mathrm{PF}_{6}$ (25)

$\mathrm{X}=\mathrm{BF}_{4}$ (26)

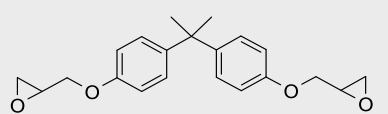

Araldite GY 260

Geltime@ $170^{\circ} \mathrm{C}$

$5 \mathrm{~min}$.

$30 \mathrm{~min}$.

not determined

aas a qualitative measure of reactivity (cure speed); time to change from the liquid phase to a stiff gel on a heated plate. At gelpoint the material is not yet fully cured!

pose. So we were then extremely pleased to find that certain dibenzylsulfonium 27 and tribenzylsulfonium salts $\mathbf{2 8}$, which had not yet been reported in the literature, showed very short cure speeds at moderate temperatures of $80-120{ }^{\circ} \mathrm{C}$ when formulated into epoxy resins - with a relatively long potlife of several days or weeks at ambient temperature. As shown in Table 2, increasing the number of benzyl groups on the sulfur resulted in a concomitant reduction of the geltimes. The introduction of benzyl carbeniumion stabilizing substituents (e.g. alkoxy groups on the phenyl ring) also markedly increased the reactivity. A very favorable balance between high cure speed and long potlife was provided by the dibenzyl-phenyl sulfonium salt 29, which was selected for further development and has found commercial application in epoxy casting resins for electronic components. Patents could be filed for these substances as well as selected applications.[11]

As an example of the many known synthesis routes for sulfonium compounds, the preparation of the tribenzyl derivative $\mathbf{2 8}$ is depicted in Scheme 4. Equimolar amounts of dibenzylsulfide $\mathbf{3 0}$ and benzyl alcohol 31 are treated with sulfuric acid at $70{ }^{\circ} \mathrm{C}$ and the hydrogensulfate salt $\mathbf{3 2}$ precipitated by pouring the reaction mixture into water. sociation of the sulfonium benzylic hetero bond into a benzyl cation $\mathbf{3 3}$ and an organic sulfide 34 in the first step. This is considered to be the slowest, rate-controlling step, requiring a relatively high activation energy $\mathrm{E}_{\mathrm{a}}$. Using simple Arrhenius plots, where the logarithm of the gel time is plotted against the reciprocal temperature, activation energies of $80-110 \mathrm{~kJ} /$ Mole were determined. Within the Arrhenius kinetic model, high activation energy results in a low reaction rate at ambient temperature and a high rate at the cure temperature - thus providing a good 'latency' of the system. In the subsequent two fast steps benzyl cation 33, the actual initiator, starts the ring-opening homopolymerization of the epoxy moiety 35 and polymerization proceeds as usual for a cationic chain growth process to yield a polyether structure 37 . In the case of polyfunctional epoxy resins, where two or more epoxy groups are attached to a molecule, this results in crosslinking of the material.

So altogether chemistry was going quite well, but were there some dark clouds creeping up on the horizon? In the late 1980s, the chemical industry worldwide had started to concentrate its resources on specific core competencies, selling off the 'foreign' businesses which had been acquired during the diversification phase. Ciba-Geigy followed suit with the electronic equipment business, and in 1989 with Ilford. A major part of the Marly site now belonged to the new owner International Paper and soon afterwards it was decided to move our 'Electronic Materials' research group back to Basel, luckily into a new building with a perfect infrastructure. The days in Marly with the cows grazing in front of the lab were to become history.

Table 2. Geltimes of benzylsulfonium salts (2 wt\% in resin) with increasing number of benzyl groups in an epoxy resin mixture (70\% GY $260+30 \%$ CY 179) antimonate in methanol provides $\mathbf{2 8}$ in $70 \%$ overall yield as colorless crystals.

A hypothetical, yet plausible mechanism for the curing reaction (Scheme 5) assumes a thermally triggered, unimolecular dis-

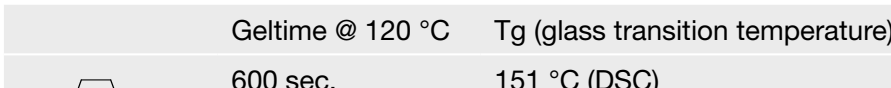

$600 \mathrm{sec}$. $151^{\circ} \mathrm{C}$ (DSC)<smiles>CC[Si](CC)Cc1ccccc1</smiles>

24

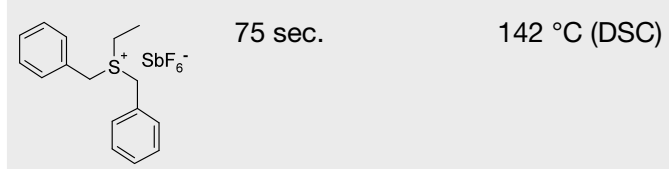

27

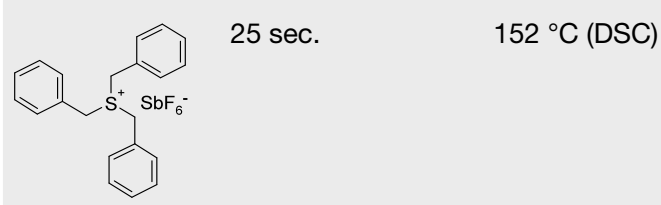


I) Unimolecular dissociation of the sulfonium salt

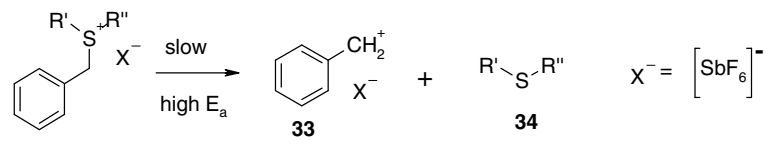

II) Cationic initiation of the epoxy homopolymerisation

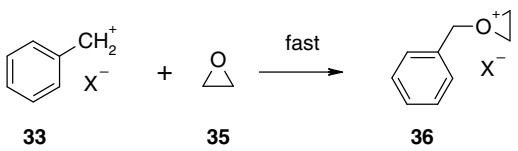

III) Propagation (chain growth) to yield polyether structure

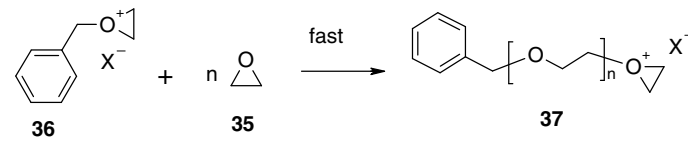

Scheme 5. Reaction mechanism (hypothetical) for the epoxy polymerization initiated by benzylsulfonium salts

CG's polymer division not only manufactured bulk amounts of epoxy resins, it also had a very substantial business with formulated materials for dedicated applications spanning a wide circle of industries. Araldite ${ }^{\circledR}$ materials for laminating, insulating and encapsulating purposes and Probimer ${ }^{\circledR}$ photopolymers and solder masks for printed circuit boards played an important role in the electrical and electronic segments. With new projects and new staff work continued in these directions.

\section{Functionalized Microgels as Latent Epoxy Curing Catalysts}

Microgels are scientifically defined as 'intramolecularly crosslinked macromolecules in a molecularly dispersed form'. Quite often, the term is used in a broader sense to describe very fine (nanometers up to $c a .1 \mu \mathrm{m}$ ), internally crosslinked particles. They have found commercial application as rheology modifiers in the coatings industry and, at that time, reports appeared in the literature describing their use as "carrier' for active chemicals such as dyes, pharmaceutical agents and enzymes. This carrier function attracted our interest and prompted us to explore the potential in the epoxy and photopolymer fields. Together with Q. Tang, S. Eldin and N. Bühler, microgels carrying various reactive species such as acrylic groups, photoinitiators or imidazoles were prepared.

The latter case proved to be especially interesting as it became apparent that such modified microgels could serve as latent catalysts in epoxy resin systems. In general, catalysts accelerate the curing reaction and allow for a shorter manufacturing time. On the other hand, in most cases their presence reduces the working window as well as the storage stability of the ready-to-use formulation, which considerably limits the ap- plication possibilities. Catalysts with high reactivity at the curing temperature and low enough reactivity at working or storage temperature, called latent catalysts, are highly desirable ( $c f$. Section 4)

Microencapsulation is one of the most common methods of providing latency to catalysts. Here the key point is a wellchosen capsule (wall) material. The capsule must be solid enough at lower temperature to ensure no release of the catalyst, whereas at the curing temperature it should permit a rapid release or fast diffusion. It is extremely difficult to find wall materials fulfilling these requirements which also possess a high resistance to the mechanical shearing forces encountered in polymer processing, especially when the formulation is filled with mineral particles. As a rule extrusion, which is a widely applied method in polymer mixing and processing, is not applicable at all.

A better 'protection' of the catalyst could be achieved by using microgel particles consisting of a continuous matrix phase with embedded imidazole catalysts. Higher catalyst loadings and better resistance to shearing forces became possible. Even when the particles were broken up, increasing the surface area, the latency was not drastically reduced. In the following, a short résumé of this work is given. ${ }^{[12]}$

Microgels are predominantly prepared via emulsion polymerization of multifunctional vinyl monomers. As a detailed description of the method is outside the scope of this article, it is sufficient to say that in general an emulsion polymerization recipe consists of the following characteristic components:

i) water as the reaction medium;

ii) more or less water insoluble monomers; iii) a surfactant and

iv) a water soluble initiator.

The final product is a 'latex': a suspension of very fine polymer particles in water where coagulation is prevented by the presence of surfactants on the surface.

To act as a carrier, reactive functional groups are needed as docking sites for the active chemical species, either on the surface or within the microgel particle. For our purpose, carboxylic acid groups seemed to be appropriate, as they allowed us to fix the imidazoles via neutralization reactions. In the example depicted in Fig. 2, a microgel is prepared from a monomer mixture containing an acrylic monomer, a crosslinker and a relatively large amount of methacrylic acid. 2,4-ethylmethylimidazol (2,4-EMI) is then added to the resulting emulsion polymer, neutralizing most of the carboxylic groups. The imidazole-modified latex has a mean particle size of about $130 \mathrm{~nm}$. The solid microgel is isolated by spray-drying the latex to yield a fine, free-flowable powder with an amine content of $2.1 \mathrm{val} / \mathrm{kg}$. If used as an accelerator in a standard epoxy/anhydride formulation, a pot-life of at least $50 \mathrm{~h}$ at $40{ }^{\circ} \mathrm{C}$ is reached (curve $\mathrm{B}$ ), whereas with a conventional amine accelerator such as benzyldimethylamine or a salt thereof with simple carboxylic acids, the pot-life is only 5-6 h (curve A). Both formulations have similar geltimes at the $120{ }^{\circ} \mathrm{C}$ cure temperature. Microgel-bound imidazoles can also be used as catalytic hardeners for the anhydride-free curing of epoxy resins via anionic polymerization of the epoxy group. Compared to neat imidazoles, storage stability of the ready-to-use mix at $40{ }^{\circ} \mathrm{C}$ increases from half a day to over 12 days. Selected microgel-imidazole products are made nowadays in multi-tonne quantities and primarily used in low pressure molding compounds for chip encapsulation.

\section{Binderpolymers for Photoimageable Soldermasks}

When the merger of Ciba-Geigy and Sandoz was broadcast on March 7, 1996 the surprise was perfect! Less astounding was the synchronous decision to integrate the industrial activities, including polymers, to form a separate, independent company - this spin off had been 'in the air'for some time as Life Sciences and Industrial Chemistry no longer had much in common. The start of Ciba Specialty Chemicals was highly acclaimed and we continued as members of the 'Research and New Applications' department under the direction of Max Hunziker.

\subsection{General Soldermask Technology}

Soldermasks play an important role in the fabrication of printed circuit boards (PCBs), where they function as a permanent, protective coating, shielding the copper circuitry from environmental effects 

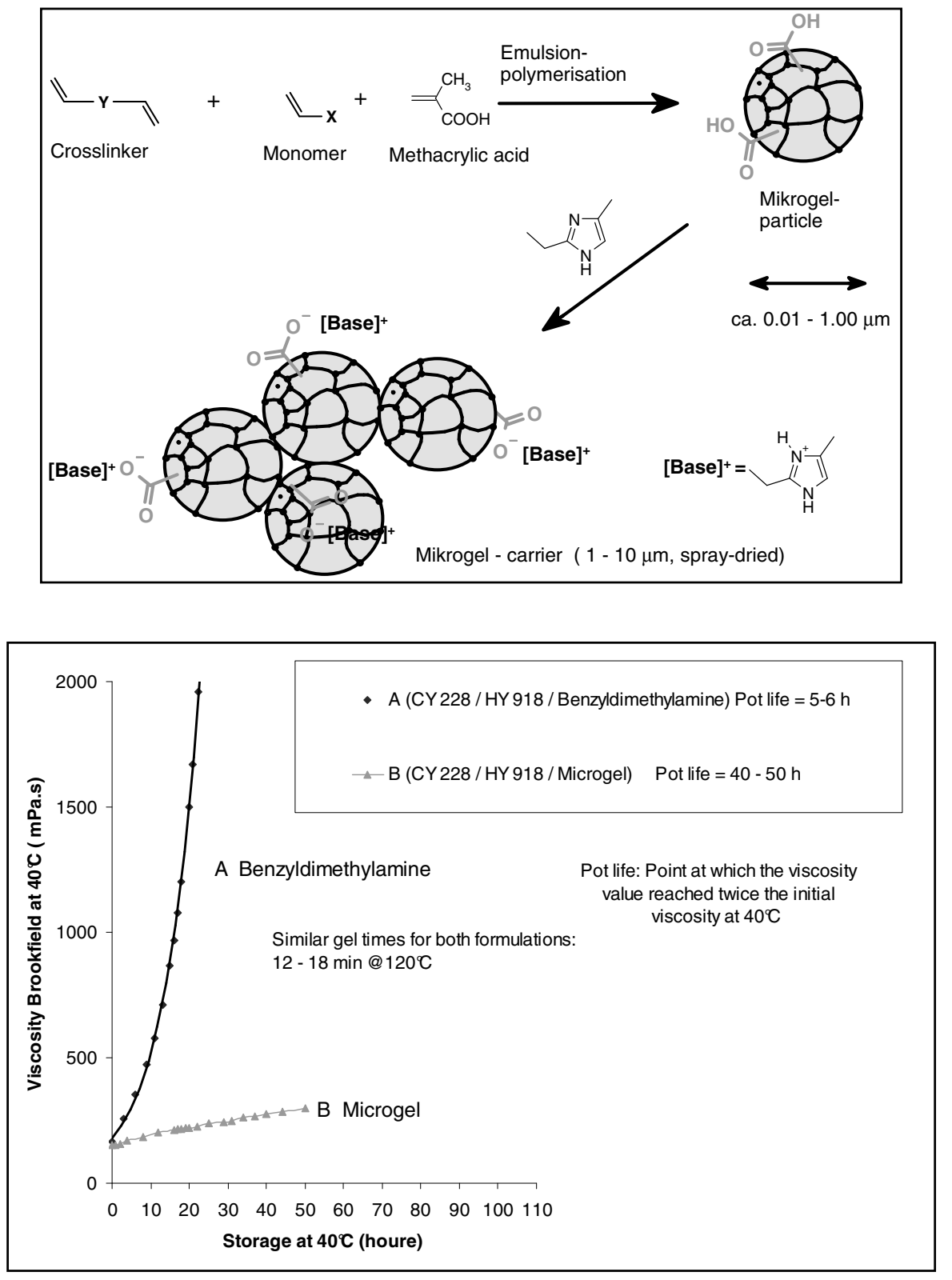

Fig. 2. Microgel carriers for imidazoles - latent curing catalysts

\section{Multilayer PCB}

(After appropriate pre-cleaning)

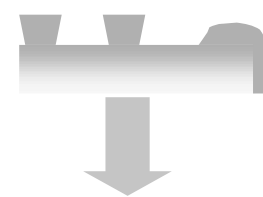

\section{Develop} (Solvent / Alkaline)

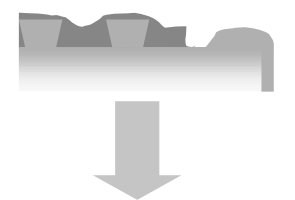

2. Coating and Drying of Soldermask (CC- / FSP-/ Spray coating)

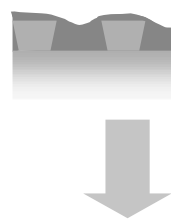

3. UV Exposure through artwork

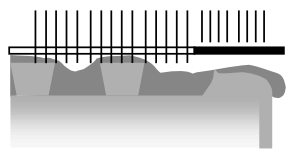

and allowing soldering at selected areas without the risk of short circuits. CibaGeigy's polymer division was a pioneer in the development of photoimageable, liquid soldermasks (Probimer ${ }^{\circledR}$ ) and nowadays Huntsman is one of the leading suppliers.

The principal process steps are schematized in Fig. 3. The PCB with copper tracks and through-holes is coated with liquid soldermask ink, either by curtain coating, flood screen printing or spray coating, leaving the through-holes open. After drying, the board is exposed with UV light through the photographic art work, crosslinking the irradiated image areas via photoinitiated polymerization of acrylic groups. Subsequently, nonirradiated image areas are dissolved away in the organic or aqueous-alkaline developer. A short, thermally or UV-light promoted cure step provides the remaining mask with additional crosslinks so that the final mechanical, electrical and thermal properties are reached.

Despite their apparently simple function, soldermask formulations are highly complex materials with recipes normally comprising 20 or more components - they also have to pass a host of test methods, as the final printed circuits may have to withstand harsh environmental conditions. The so-called binderpolymers constitute the major part of a ready-to-use formulation $(25-30 \%)$ - the remainder consists of low molecular weight, multifunctional acrylates $(5-10 \%)$, the photoinitiator system ('photopackage', 4-8\%), various coating additives $(\sim 10 \%)$, mineral fillers $(\sim 20 \%)$ and solvent $(22-36 \%)$.

\subsection{Binderpolymers for Soldermasks}

Most of the desirable properties are directly influenced by the choice of the polymeric binders - they determine the film forming ability, the type (organic, aqueous alkaline) and speed of development, the drying properties and, last but not least, the thermal, mechanical and dielectric quality of the final coating on the printed circuit board. From a chemical viewpoint they represent high molecular weight copolymers with specific functional groups, particularly acrylic groups and acid groups in case of alkaline developable products. Due to the presence of photopolymerizable acrylic groups the photosensitivity is enhanced and the binder becomes an integral part of the entire crosslinked matrix, concomitantly improving mechanical and thermal end properties. The acid groups render the unexposed coating more or less soluble in the aqueous, $1 \%$ sodium carbonate developer medium. Mainly carboxylic groups are used as acidic functions; they are easily accessible by a diversity of synthetic methods and are compatible with other 
functional groups that might also be present on the polymer.

In general, binderpolymers should provide the following properties:

i) high photosensitivity and resolution,

ii) fast development without formation of residues,

iii) excellent electrical and mechanical properties and stability in post-soldermask processes (e.g. soldering, metallization processes),

iv) low production costs.

The last point may need some explanation: cost has become a crucial factor as soldermasks are not considered a real specialty any more and fierce competition from Asia, both price- and quality-wise, is ever growing. Printed circuit board manufacturing has also dramatically shifted to the east with China being today's biggest producer of PCBs. Consequently, low manufacturing costs are of utmost importance, necessitating inexpensive, registered raw materials and straightforward synthesis routes. As production volumes of up to several hundred tonnes per year are anticipated, easily scalable and robust production processes are required.

The synthesis of high molecular weight binderpolymers, especially by Japanese companies, is amply documented in the patent literature. Nonetheless, keeping in mind the cost restrictions mentioned above, only a handful of concepts are really used in production. One of these, the epoxyacrylate structural motif, plays a very important role (Scheme 6).

The rather misleadingly named epoxyacrylates $\mathbf{4 0}$ are prepared by the ring opening addition of acrylic acid 39 to epoxy compounds 38 , forming $\beta$-hydroxy-acrylic esters 40. Epoxy novolacs and bisphenol A type diglycidylethers are preferred starting materials 38 and their reaction products form the basis of many commercial UV curable formulations. Usually the reaction is run with a catalyst to achieve reasonable reaction rates at temperatures around $100{ }^{\circ} \mathrm{C}$. Known catalysts are tertiary amines, quaternary ammonium salts, triphenyl phosphine and chromium(III) salts of aliphatic carboxylic acids, such as octanoic acid. Superior results are achieved with either triphenyl phosphine or the chromium(III) salts. Another important aspect is the choice of a polymerization inhibitor, which prevents an uncontrolled, highly exothermic acrylic polymerization during the preparation. Without the addition of an inhibitor, the reactions tend to gel after a short time with the concomitant liberation of dangerous amounts of heat. Hydroquinone derivatives in the presence of a certain amount of oxygen are highly efficient inhibiting systems and routinely used in production. Higher molecular weight epoxyacrylates $\mathbf{4 0}$ constitute im-

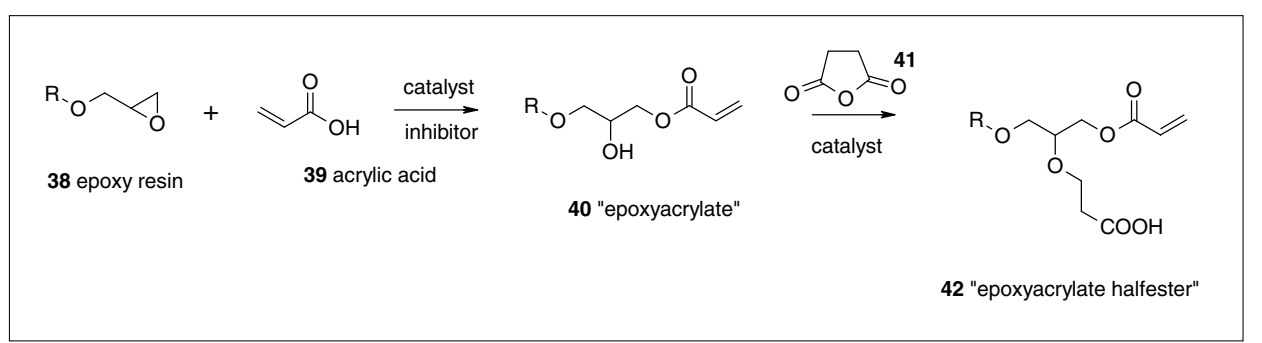

Scheme 6. Synthesis of epoxy acrylates and their half-ester derivatives

portant binders in organic developable soldermask formulations.

The secondary $\mathrm{OH}$-groups of the epoxyacrylates $\mathbf{4 0}$ can be further reacted with cyclic anhydrides, e.g. succinic anhydride 41, to yield half-ester derivatives 42 containing carboxyl groups. The same catalysts as in the first step can be used to improve reaction rates (with the exception of the $\mathrm{Cr}(\mathrm{III})$ salts) and inhibition is also required An important pre-requisite is that no epoxy groups from the first step are left over, otherwise the anhydride-epoxy curing reaction will lead to a solid lump of gelled epoxy resin in the reaction vessel! It is not necessary to react all of the secondary $\mathrm{OH}$-groups in $\mathbf{4 0}$ and usually only a partial half-esterification, yielding the desired acid value, is carried out. Resins of the type $\mathbf{4 2}$ combine acrylic and carboxylic functionality in one molecule, rendering them especially suitable for aqueous alkaline developable photoresists.

Our work on proprietary, tailor-made binderpolymers extended over many years and allowed us not only to achieve a competitive technical advantage but also provided a prime potential for cost savings through inhouse production, thus avoiding transportation, logistics and storage costs. Thanks to the extensive work of the chemical process development department in Monthey (Alain Klose and team) on up-scaling and optimizing the procedures, these materials can now be produced in volumes of several hundred tons per year.

In the year 2000, Ciba SC decided to disinvest their Performance Polymer division, as it no longer fitted into long-term strategic requirements. Morgan Grenfell, a private equity firm, took over our division and newly named it Vantico. Being now in company with Formula 1 racing teams and horse-race betting offices, many of us were asking if such a bank could manage a chemical company. The answer was quite simple as in 2003 the then privately owned firm Huntsman appeared on the scene as a 'white knight' and took over Vantico only just in time! To be fair though, the Vantico intermezzo took place in a rather difficult period of time characterized by a stuttering economy and political uncertainty due to 9/11. The positive impact of Huntsman could be immediately felt even at lower lev- els, as clear regulations for the daily work and a scrupulous project management were speedily implemented. As part of the Huntsman Advanced Materials business unit we continued our work on binderpolymers with a reassured and motivated team.

\subsection{Binderpolymer for Aqueous- Alkaline Developable Soldermasks}

The dispute as to which of the two basic concepts for soldermasks, organic or aqueous-alkaline developable, gives the best overall performance is nearly as old as the technology itself. From a purely chemical point of view it seems reasonable that an organic matrix without strong hydrophilic carboxylic groups will provide better electrical insulating properties, especially in humid environmental conditions. On the other hand, an organic developer solvent mandates special precautions in the processing equipment regarding flammability and solvent recovery - at additional cost. The fact is that nowadays, especially in Asia, the majority of soldermasks are developed using aqueous sodium carbonate solutions with relatively inexpensive developer equipment.

Scheme 7 depicts one of our more recent approaches to obtain suitable binderpolymers for aqueous development, based on so-called 'postglycidylated' epoxy resins.[13] A commercial, solid epoxy resin 43, e.g. an Araldite ${ }^{\circledR}$ GT type, is used as starting material. The secondary hydroxyl groups of this resin are first glycidylated with epichlorohydrin to yield the postglycidylated epoxy resin $\mathbf{4 4}$ with a markedly increased epoxy group content. The reaction is performed as a so-called azeo process: a concentrated sodium hydroxide solution is gradually added to the solution of 43 in excess epichlorohydrin and water is azeotropically removed with epichlorohydrin as carrier under reduced pressure. Small amounts of tetramethyl ammonium chloride (TMAC) are known to catalyze the reaction. $\mathbf{4 4}$ is transformed into the epoxyacrylate $\mathbf{4 5}$ by catalyzed addition of acrylic acid to all of the epoxy groups and $\mathbf{4 5}$ is then further modified by partial reaction of some of the secondary hydroxyl groups with a cyclic anhydride, thus introducing the necessary amount of carboxylic acid groups. The last two steps 
can be combined into a one-pot reaction sequence and nowadays binderpolymers of the type $\mathbf{4 6}$ are commercially produced in multi-tonne batches. Soldermasks derived from these binders show improved flexibility and toughness and also excellent thermal shock behavior and resistance in thermal cycling tests. Consequently they are specially suited for PWBs designed for the harsh and demanding environments in automotive applications.

\section{Conclusions}

The current perspectives for parts of the industrial chemistry in our region appear to be less optimistic than 35 years ago - with ever-increasing price pressure from low-cost countries and the shift of technology driven businesses to Asia. However bearing in mind today's growing number of academic groups involved in macromolecular and related research topics, new applications of macromolecules and polymer technology in the areas of life sciences and information technology are to be expected, thus providing new growth and creating new jobs in our industry.

\section{Acknowledgments}

The author would like to thank the many colleagues and co-workers who helped and supported him on this 'odyssey', some of whom have been mentioned in the text and in the references. A special thanks goes to all the laboratory technicians who carefully carried out the thousands of experiments without a single incident - to name a few: Petra Ankli, Hans Bläuer, Stefan Burkhard, Hubert Dafflon, Jean Stoffer and Beatrice Zurkinden.

Received: May 8, 2008

[1] D. Lohmann, P. Furrer, R. Darms, G. Greber, US Patent 4124 651, Prio. 25.08.1972 to Ciba-Geigy.

[2] M. Roth, US Patent 4132 715, Prio. 09.04.1976 to Ciba-Geigy.

[3] a) H. Zweifel, Photogr. Sci. Eng. 1983, 27, 114; b) J. Finter, E. Widmer, H. Zweifel, Angew. Makromol. Chem. 1984, 128, 71; c) J. Finter, Z. Haniotis, F. Lohse, K. Meier, H. Zweifel, Angew. Makromol. Chem. 1985, 133, 147.

[4] a) M. Baumann, H. Bosshard, Helv. Chim. Acta 1978, 61, 2751; b) M. Baumann, H. Bosshard, W. Breitenstein, G. Rihs, T. Winkler, Helv. Chim. Acta 1984, 67, 1897; c) M. Baumann, W. Breitenstein, EP-A 0174272, Prio. 15.08.1984 to CibaGeigy; d) M. Baumann, W. Breitenstein, EP-A 0175641, Prio. 15.08.1984 to CibaGeigy.

[5] a) M. Baumann, V. Kvita, M. Roth, J. S. Waterhouse, US Patent 4107 174, Prio 18.06. 1975 to Ciba-Geigy; N. Baumann, H. Zweifel, M. Baumann, J. S. Waterhouse, US Patent 4158 730, Prio. 18.06.1975 to Ciba-Geigy.

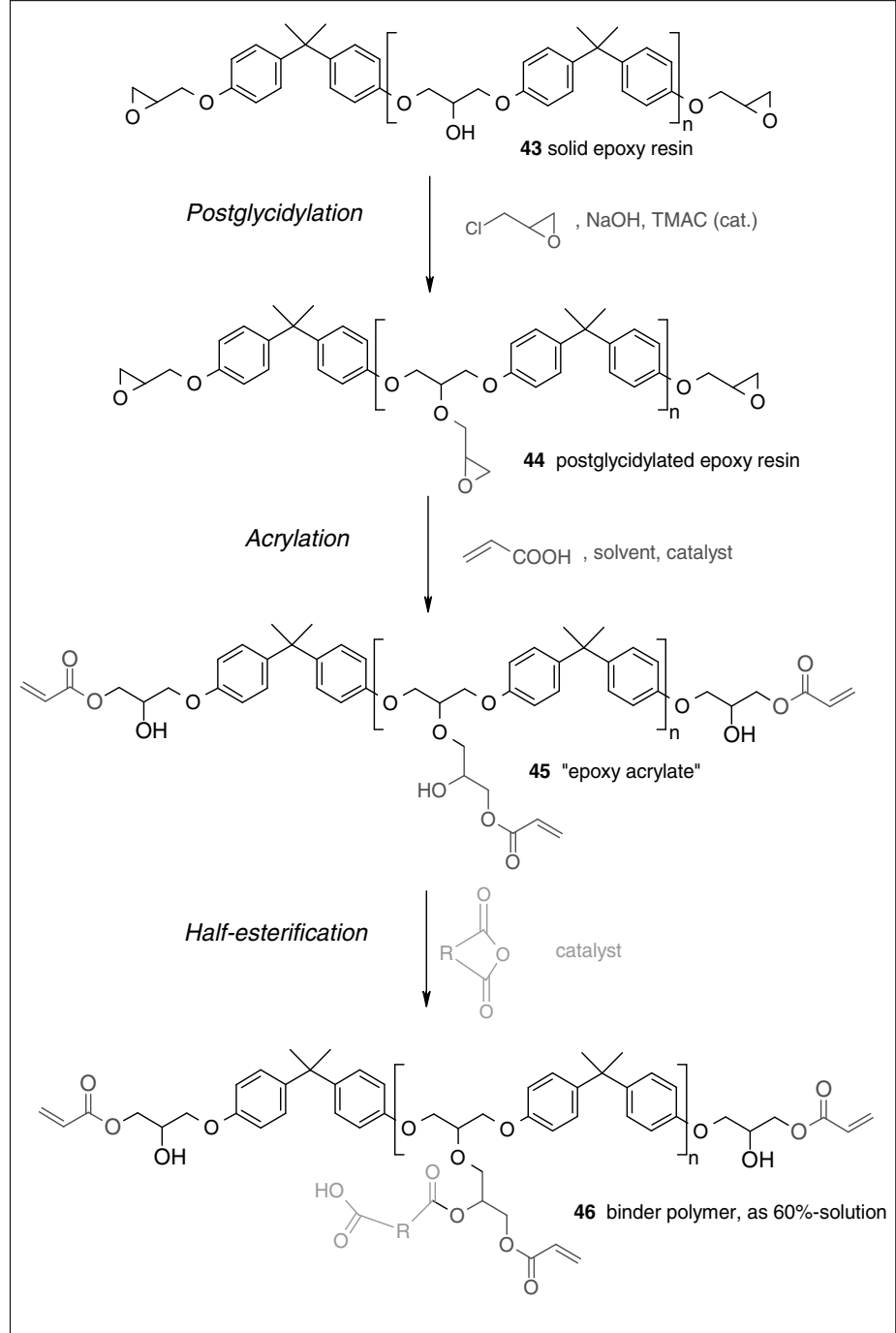

Scheme 7. Binderpolymer for an aqueous-alkaline developable soldermask

[6] a) J. Berger, H. Zweifel, Angew. Makromol; Chem. 1983, 115, 163; b) B. Müller, EP-A 0072 780, Prio. 17.08.1981 to Ciba-Geigy.

[7] K. Meier, H. Zweifel, J. Photochem. 1986 35, 353.

[8] a) M. Roth, B. Müller, J. Berger, P. Loew, US Patent 4626 497, Prio. 18.05.1979 to Ciba-Geigy; b) B. Müller, M. Roth, EP-A 0040 583, Prio. 21.05.1980 to Ciba-Geigy; c) M. Roth, B. Müller, S. R. Postle, EP-A 0078 233, Prio. 15.10.1981 to Ciba-Geigy; d) M. Roth, EP 0094913 Prio. 19.05.1982 to Ciba-Geigy; e) $\mathrm{M}$ Roth, B. Müller, Polymers Paint Color J 1988, 178, 209.

[9] a) S. P. Pappas, L. W. Hill, J. Coatings Technol. 1981, 53, 43; b) S. P. Pappas, H. B. Feng, in 'Cationic Polymerization and Related Process', Ed. E. J. Goethals, Academic, New York, 1984, p. 325.

[10] a) JP 56152833, Prio. 30.04.1980 to Asahi Denka Kogyo KK; b) JP 58037003, Prio. 28.08.1981 to Asahi Denka Kogyo KK; c) K. Morio, H. Murase, H. Tsuchiya, T. Endo, J. Appl. Polym. Sci. 1986, 32, 5727; d) B. Stapp, L. Schön, H. Bayer, M. Hoffmann, Angew. Makromol. Chem. 1993, 209, 197; e) J.A. McGowen, L.J.
Mathias, Polym. Compos. 1997, 18 348.

[11] a) M. Roth, B. Müller, EP 0379 464, Prio. 16.01.1989 to Ciba-Geigy; b) K. Munk, M. Roth, EP 0424 314, Prio. 18.10.1989 to Ciba-Geigy; c) T. Haug, B. Müller, M. Roth, EP 0508 952, Prio. 08.04.1991 to Ciba-Geigy; d) D. Baumann, W. Margotte, B. Müller, EP 0508 951, Prio. 08.04.1991 to Ciba-Geigy; e) K. Munk, EP 0527 107, Prio. 19.06.1991 to CibaGeigy; f) B. Müller, EP 0580 552, Prio. 21.07.1992 to Ciba-Geigy.

[12] a) Q. Tang, M. Roth, D. T. Behm, C. W. Mayer, K. Petschel, S. H. Eldin, EP 0776 917, Prio. 29.11.1995 to Ciba-Geigy; b) M. Roth, Q. Tang, S. H. Eldin, EP 0816 393, Prio. 02.07.1996 to Ciba-Geigy; c) Q. Tang, G. Reitmajer, M. Roth, M. Spitzer, P. D. Willis, EP 1163 280, Prio. 17.03.1999 to Ciba-Geigy.

[13] M. Roth, R. Salvin, K. Meier, B. Sailer, R. Wiesendanger, EP 0632 078, Prio. 02.07.1993 to Ciba-Geigy. 